\title{
Compressive properties of sandwiches with functionally graded rubber core and jute-epoxy skins
}

\author{
M R DODDAMANI* and S M KULKARNI ${ }^{\dagger}$ \\ Mechanical Engineering, B. V. B. College of Engineering and Technology, Hubli, India \\ ${ }^{\dagger}$ Mechanical Engineering, National Institute of Technology Karnataka, Surathkal, India
}

MS received 19 December 2010; revised 1 November 2012

\begin{abstract}
The compressive behaviour of a new class of sandwich composite made up of jute fiber reinforced epoxy skins and piece-wise linear fly ash reinforced functionally graded (FG) rubber core is investigated in flat-wise mode. FG samples are prepared using conventional casting technique. Presence of gradation is quantified physically by weight method. This paper addresses the effect of weight fraction of fly ash, core to thickness ratio $(\mathrm{C} / \mathrm{H})$ and orientation of jute on specific compressive modulus and strength. In each trial five replicates are tested with lower amount of fly ash below the upper skin of sandwich (rubber-up). Results of experimentation are subjected to statistical analysis of variance (ANOVA) to find the influential factor governing the compressive behaviour. Furthermore piece-wise linear gradation is modeled in finite element and strength values are compared with experimental results. Sandwich sample with fly ash content of $40 \%, \mathrm{C} / \mathrm{H}$ of 0.4 and orientations of $30^{\circ} / 60^{\circ}$ registered better performance. Specific strength is observed to increase upto $30 \%$ filler content followed by stabilization. Finite element results for strength match very well with experimental ones.
\end{abstract}

Keywords. Compressive; sandwich; piece-wise linear; functionally graded; specific modulus; finite element.

\section{Introduction}

The increasing efforts in developing light weight structures with better mechanical performances, in recent years, has led to wide usage of sandwich composites mainly in land and sea transportation (Atckinson 1997). These composites are popular due to high specific strength and stiffness. Sandwiches are composed of two stiff, strong and thin faces (skins) bonded to a light and thick weaker core (ASTM C 274-07 1999). Faces sustain in-plane and bending loads, while the core resist transverse shear forces and keep the facings in place. These provide an increased flexural rigidity and strength by virtue of their geometry. The high specific strength and stiffness make them ideal in structural design (Vinson 1999; Gdoutos and Daniel 2008). Developments in aviation posed requirement of light weight, high strength and highly damage tolerant materials. Sandwich composites, fulfilling these requirements became the first choice for many applications including ground transport and marine vessels (Venkata Dinesh Muthyala 2007). Polymer sandwich constructions are preferred over conventional materials because of their high corrosion resistance (Russo and Zuccarello 2007). Because of these advantages, sandwich structures have been widely used in the automotive, aerospace, marine and other industrial applications. These also draw a lot of interest in the

\footnotetext{
*Author for correspondence (mrd_phd@ @rediffmail.com)
}

construction industry and is now used in civil engineering applications (Keller 2006). Recent applications have demonstrated that fiber composite sandwich construction can be effectively and economically used in the civil infrastructure (Manalo et al 2010). Other structures constructed using this concept is highway bridge deck systems (Davalos et al 2001) and temporary bypass roadways (Rocca and Nanni 2005).

The present interest in sandwich construction with fiber composites as skin materials is because of their high stiffness and their compatibility with different core materials. Normally, the core is low strength foam material with its thickness providing the necessary high stiffness with overall lower density (Daniel and Abot 2000). These types of sandwich composites are sensitive to failure by the application of compressive loads (Dai and Thomas 2003). Conventional sandwich structures subjected to compressive loads are expected to possess uniform stiffness. A sandwich whose stiffness increases with the load applied can serve some application better as against conventional sandwiches (Doddamani and Kulkarni 2009). Thus, any further enhancement of sandwich structural performance for critical applications should potentially include new ideas without compromising existing benefits. This can be potentially accomplished by incorporating novel material construction concepts as well as newer class of materials for the face sheets and the core (Kirugulige et al 2005). Hence a sandwich having a core of functionally graded material (FGM) is taken up for the present analysis. Such a sandwich could be realized by using a functionally graded (FG) core (Doddamani et al 2011). 
Complexity in analysis of FG cores necessitates increasing thrust to understand the behaviour of constituents in particular core of sandwiches (Sankar 2001; Anderson 2003; Apetre et al 2003; Kirugulige et al 2005). FGM's are those in which properties change from point to point within them. FGM's have gained large applicability as thermal-barriers (Chakraborty et al 2003). As many of the polymeric systems used for developing FGM's are generally associated with the tag of expensiveness, it is decided to examine the gradation in composition and its subsequent behaviour under compression when an abundantly available lower density possessing fly ash is used as filler material for the core. Fly ash is a fine particulate waste product derived during the generation of power in a thermal power plant. These are inexpensive, possess good mechanical properties and have aspect ratios closer to unity thereby are expected to display near isotropic characteristics. When used with well established matrix systems, these help in reducing the cost and either retain or improve desirable and specific mechanical properties. Fly ash has attracted interest lately because of the abundance in terms of volume of the material generated and the environmentallinked problems in the subsequent disposal. Fly ash mainly consists of alumina and silica which are expected to improve the composite properties. It also consist hollow spherical particles (termed as cenospheres) which aid in maintaining lower density values for the composite. This feature is of considerable significance in weight specific applications. As the fillers are of near spherical shape, the resin spread is better (Doddamani and Kulkarni 2012). Use of fly ash by exploiting its three tier particle structure (solid, hollow and plerospheres) which might aid in building FG composites is not explored yet. Developing newer and utilitarian functionally graded systems using ashes is an interesting and challenging task.

Though the concept of FG core in a sandwich and its implication on mechanical performance of sandwich structures is available in early literature (Mouritz and Thomson 1999; Evans et al 2001; Najafizadeh and Eslami 2002; Shen 2002; Shen and Leung 2003; Wadley et al 2003; Bull and Edgren 2004; Ma and Wang 2004; Shen 2005), experimental investigation of compressive properties of sandwiches with FG core reinforced with fly ash is seldom reported.

In this paper, compressive behaviour of a structural sandwich composites made up of fly ash reinforced rubber core and jute-epoxy skins is reported experimentally. Specific modulus and strength are evaluated in flat-wise compression. Sandwiches are prepared and tested according to combination of levels of parameters as suggested in L9 orthogonal array (OA) (Ross 1988; Montgomery 2001). Modulus and strength values obtained from experimental results are statistically analysed to identify the influencing factors. The study considers three factors with each factor at three different levels. Material parameter is considered as one of the factor with variation of weight fraction of fly ash as 20,30 and $40 \%$. Geometrical parameters include ratio of core thickness to total thickness of sandwich i.e. $\mathrm{C} / \mathrm{H}$ ratio $(0.4,0.6$, $0.8)$ and orientation of fibers in jute fabric $\left(0^{\circ} / 90^{\circ}, 30^{\circ} / 60^{\circ}\right.$, $45^{\circ} / 45^{\circ}$ ). Finally experimental results of specific strength are compared with finite element model simulating piece-wise linear gradation.

\section{Experimental}

\subsection{Materials}

The matrix system consists of natural latex supplied by Karnataka Forest Development Corporation Ltd., Rubber division, Sullia, Karnataka, India. The density of latex is found to be $1060 \mathrm{~kg} / \mathrm{m}^{3}$. The filler, fly ash is obtained from Raichur Thermal Power Plant, Raichur, Karnataka, India. This ASTM class ' $C$ ' fly ash with bulk density of about $900 \mathrm{~kg} / \mathrm{m}^{3}$ is found to consist of a mixture of solid and hollow spheres of assorted sizes. Energy dispersive spectroscopy of the fly ash sample revealed the main constituents to be silica (63\%) and alumina (26\%) (Kishore et al 2002). Physical properties of the natural latex and fly ash are presented in table 1. Compositional details of fly ash particle are tabulated in table 2.

\subsection{Plan of the experiment}

Experiments are planned based on L9 orthogonal array (OA) (Montgomery 2001). Table 3 shows details of the

Table 1. Properties of materials used in FG core.

\begin{tabular}{lccc}
\hline Material & $\begin{array}{c}\text { Young's modulus } \\
\left(\mathrm{N} / \mathrm{m}^{2}\right)\end{array}$ & $\begin{array}{c}\text { Density } \\
\left(\mathrm{kg} / \mathrm{m}^{3}\right)\end{array}$ & $\begin{array}{c}\text { Poisson's } \\
\text { ratio }\end{array}$ \\
\hline Latex & $1 \cdot 00 \mathrm{E}+09$ & $1 \cdot 06 \mathrm{E}+03$ & 0.49 \\
Fly ash & $9 \cdot 80 \mathrm{E}+10$ & $2 \cdot 25 \mathrm{E}+03$ & 0.21 \\
\hline
\end{tabular}

Table 2. Compositional details of fly ash particle.

\begin{tabular}{lc}
\hline Constituent & Weight \% \\
\hline $\mathrm{SiO}_{2}$ & 63 \\
$\mathrm{Al}_{2} \mathrm{O}_{3}$ & $26 \cdot 55$ \\
$\mathrm{CaO}$ & 0.42 \\
$\mathrm{Fe}_{2} \mathrm{O}_{3}$ & $6 \cdot 7$ \\
$\mathrm{TiO}_{2}$ & 2.47 \\
\hline
\end{tabular}

Table 3. Factors and levels selected for the present study.

\begin{tabular}{lccc}
\hline & \multicolumn{3}{c}{ Factors } \\
\cline { 2 - 4 } Levels & $\begin{array}{c}\text { Weight fraction } \\
\text { of fly ash (\%) } \\
\text { (factor 1) }\end{array}$ & $\begin{array}{c}\text { C/H ratio } \\
\text { (factor 2) }\end{array}$ & $\begin{array}{c}\text { Orientation of } \\
\text { jute fabric } \\
\text { (factor 3) }\end{array}$ \\
\hline Level 1 & 20 & 0.4 & $0^{\circ} / 90^{\circ}$ \\
Level 2 & 30 & 0.6 & $30^{\circ} / 60^{\circ}$ \\
Level 3 & 40 & 0.8 & $45^{\circ} / 45^{\circ}$ \\
\hline
\end{tabular}


Table 4. Sample coding for sandwich specimens.

\begin{tabular}{ll}
\hline Sample code & \multicolumn{1}{c}{ Description } \\
\hline$W_{\mathrm{a}} R_{\mathrm{b}} O_{\mathrm{c}}$ & Sandwich specification \\
$W$ & Indicates factor 1 (weight\% of fly ash) \\
$\mathrm{a}$ & Levels of factor 1 in \% $(20,30,40)$ \\
$R$ & Indicates factor 2 (C/H ratio) \\
$\mathrm{b}$ & Levels of factor 2 $(0 \cdot 4,0 \cdot 6,0 \cdot 8)$ \\
$O$ & Indicates factor 3 (jute skin orientation) \\
$\mathrm{c}$ & Levels of factor 3 $\left(0^{\circ} / 90^{\circ}, 30^{\circ} / 60^{\circ}, 45^{\circ} / 45^{\circ}\right)$ \\
\hline
\end{tabular}

Table 5. Jute layers for different $\mathrm{C} / \mathrm{H}$ ratios.

\begin{tabular}{ccccc}
\hline C/H & $\begin{array}{c}\text { Core } \\
\text { thickness, } \\
\text { ratio }\end{array}$ & $\begin{array}{c}\text { Number } \\
\text { of jute } \\
\text { layers } \\
\text { below core }\end{array}$ & $\begin{array}{c}\text { Number } \\
\text { of jute } \\
\text { layers } \\
\text { above core }\end{array}$ & $\begin{array}{c}\text { Sandwich } \\
\text { thickness, }\end{array}$ \\
\hline $0 \cdot 4$ & 4 & 6 & 6 & 10 \\
$0 \cdot 6$ & 6 & 4 & 4 & 10 \\
$0 \cdot 8$ & 8 & 2 & 2 & 10 \\
\hline
\end{tabular}

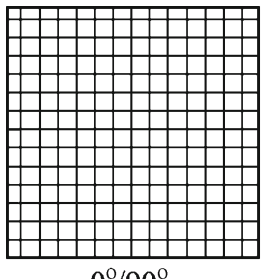

$0^{\circ} / 90^{\circ}$

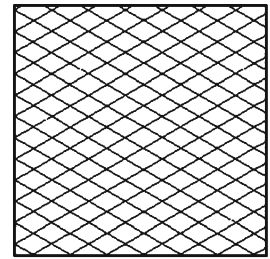

$30^{\circ} / 60^{\circ}$

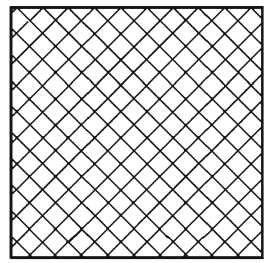

$45^{\circ} / 45^{\circ}$ (a)
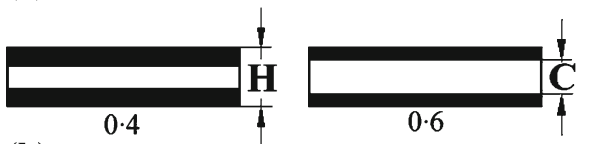

(b)

Figure 1. (a) Orientation of jute skin, (b) variation of core thickness, $(\mathrm{C})$ to total thickness $(\mathrm{H})$.

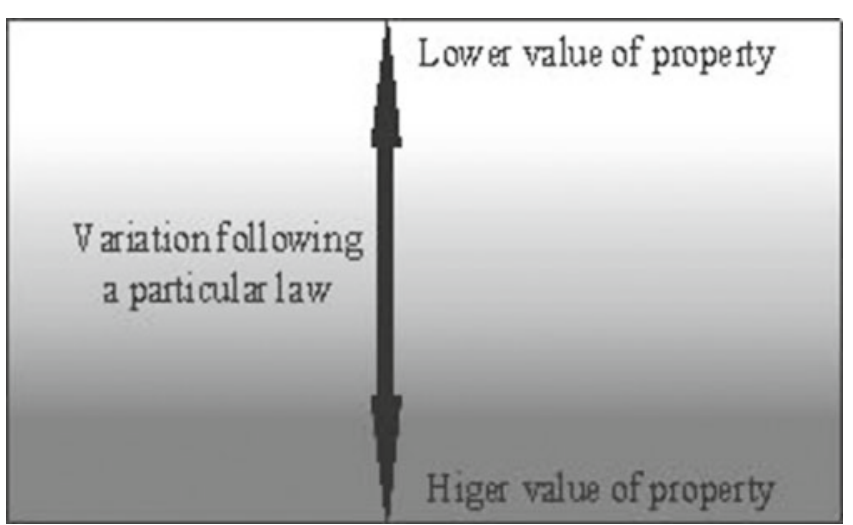

Figure 2. Rubber-up configuration.

factors and levels taken into account in the present work. Table 4 presents sample coding used for sandwich samples.
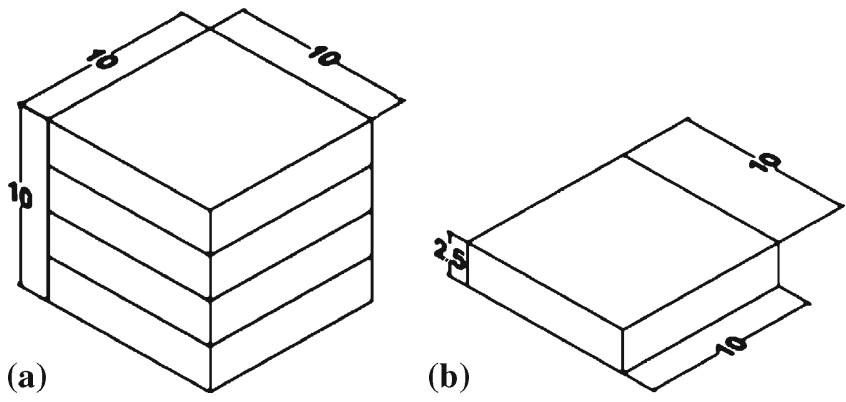

Figure 3. (a) FG core sample and (b) slice cut from sample.

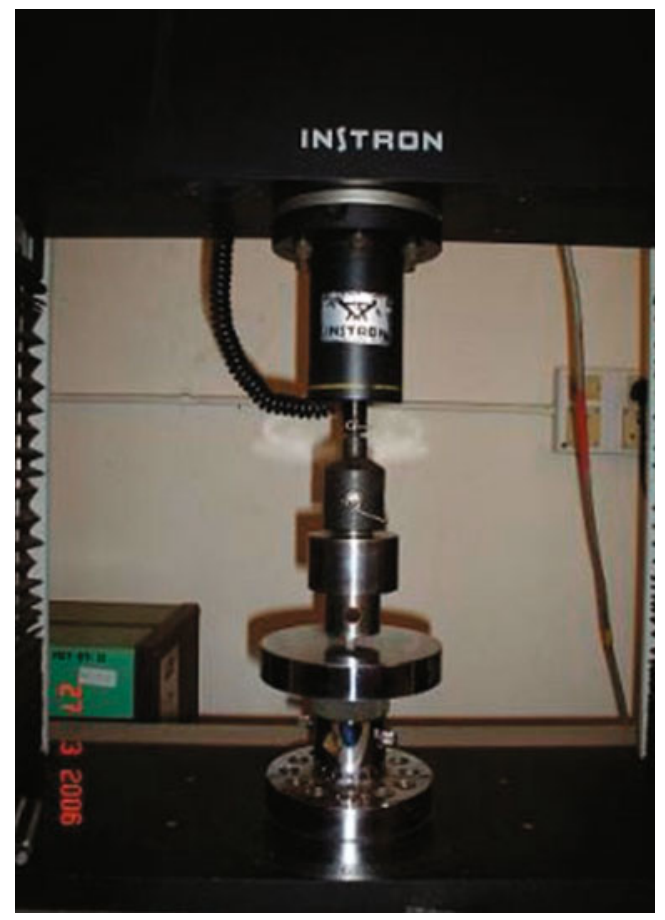

Figure 4. Compression test set-up.

\subsection{Processing}

For processing of FG cores, conventional casting technique is utilized. Fly ash, the filler used for core as emphasized earlier consists of a mixture of solid, hollow and composite particles possessing different densities and resembling spherical in form to a larger degree. The gradation in the core is expected due to differential settling of these particles. A measured quantity of natural latex is mixed with pre-weighed amounts of fly ash, sulphur (vulcanizer) and zinc oxide (catalyst) (Blackley 1997) by gentle stirring for about $1 \mathrm{~h}$. The mold employed for preparation of core specimen $(58 \mathrm{~mm} \times$ $58 \mathrm{~mm} \times 10 \mathrm{~mm}$ ) is completely covered on all sides with teflon sheet. Initially silicone releasing agent is applied to the mold to facilitate ease of removal of the cast sample. The mixture is then slowly decanted into the mold cavity followed by curing at $90^{\circ} \mathrm{C}$ in an oven for about $5-6 \mathrm{~h}$. This procedure is carried out for all samples having 20, 30 and $40 \%$ 


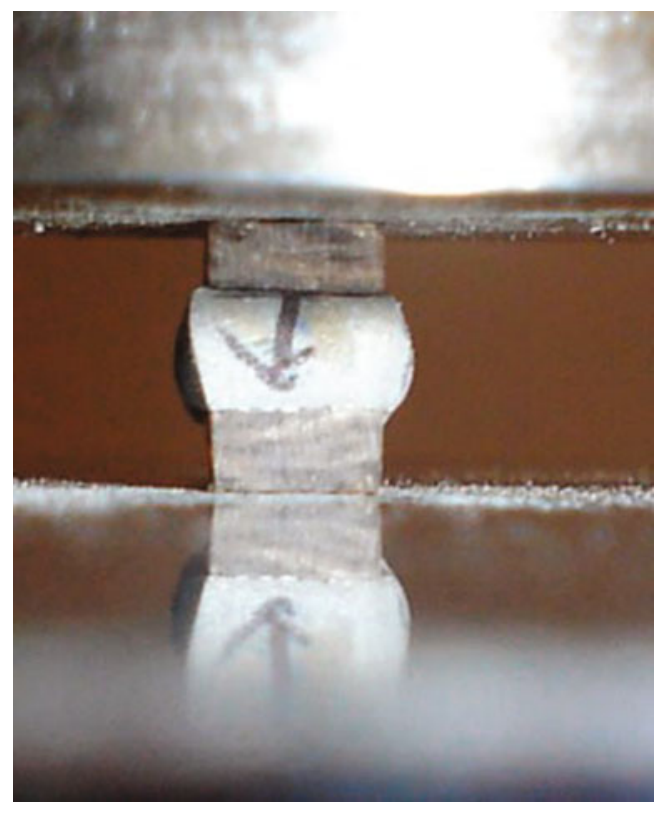

Figure 5. Test in progress.

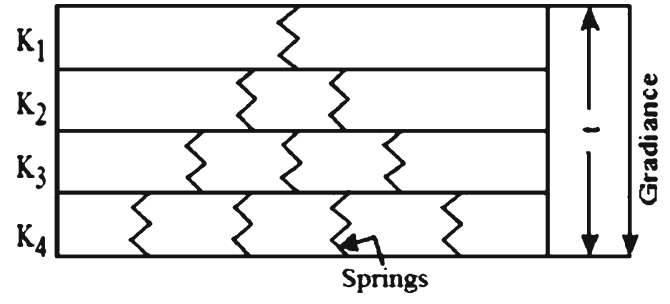

Figure 6. Spring analogy for gradation simulation in FEA. fly ash by weight. Finally, the cured core sample is removed from the mold and the edges are trimmed.

To prepare the sandwich skins, a bi-directional woven jute fabric procured from M/S Barde Agencies, Belgaum, Karnataka, India is used. This fabric is cut into layers of dimensions $55 \mathrm{~mm} \times 55 \mathrm{~mm}$ in required orientation. Thickness of each fabric piece is $0.5 \mathrm{~mm}$. All the layers of jute fabric are heated in an oven at $70{ }^{\circ} \mathrm{C}$ for $5-10 \mathrm{~min}$ to remove the moisture present. Based on required $\mathrm{C} / \mathrm{H}$ ratio, numbers of fabric layers to be used are determined (table 5).

Prepared sandwich slabs are schematically illustrated in figure 1, showing top view (figure 1a) with different orientations and front view (figure $1 \mathrm{~b}$ ) with varying $\mathrm{C} / \mathrm{H}$ ratio.

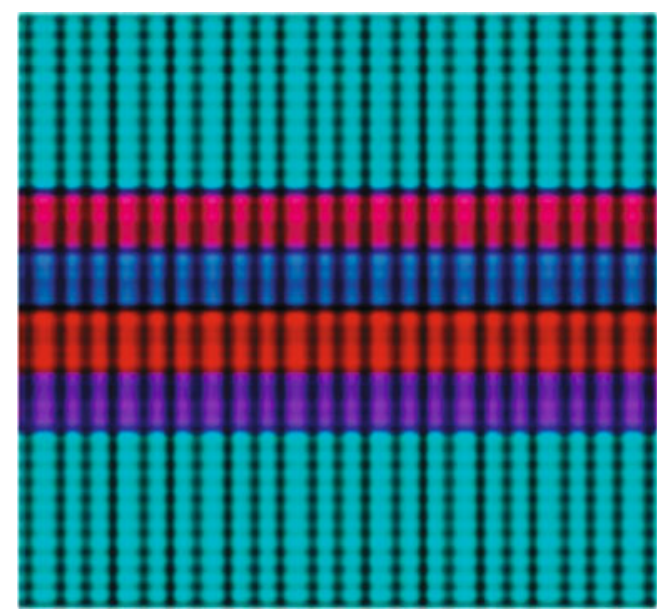

Figure 7. Finite element mesh for FG sandwich.

Table 6. Core and skin properties used in FEA.

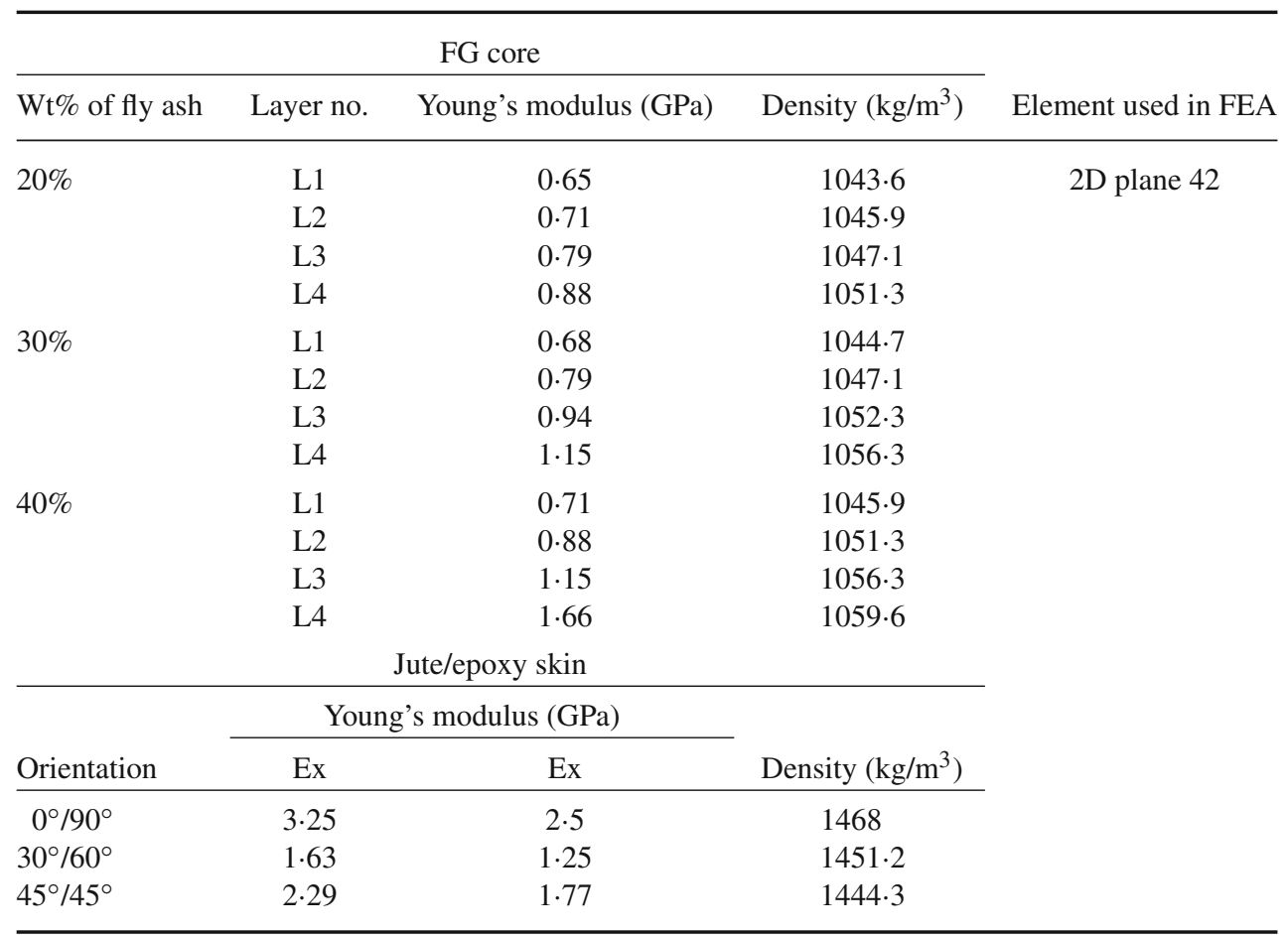

L - layer, ${ }^{*} \mathrm{~L} 1$ - for layer and L4 - bottom layer. 


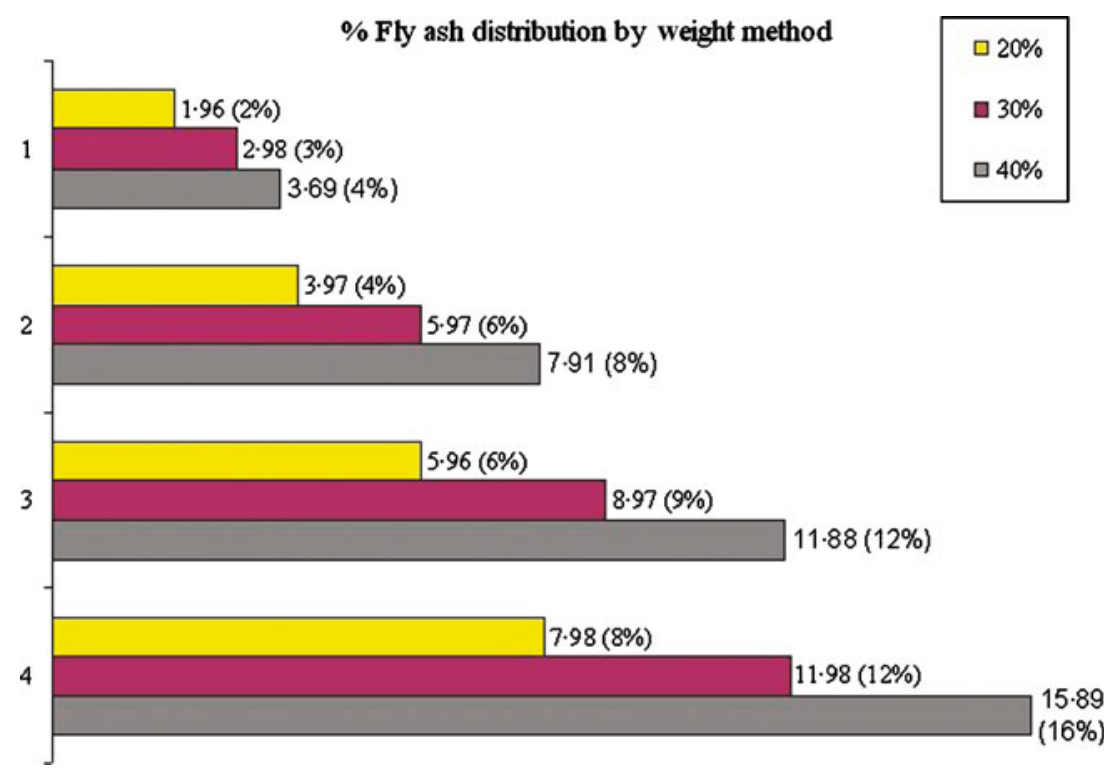

Figure 8. Layer wise \% fly ash weight distributions (1 - top layer, 4 - bottom layer).

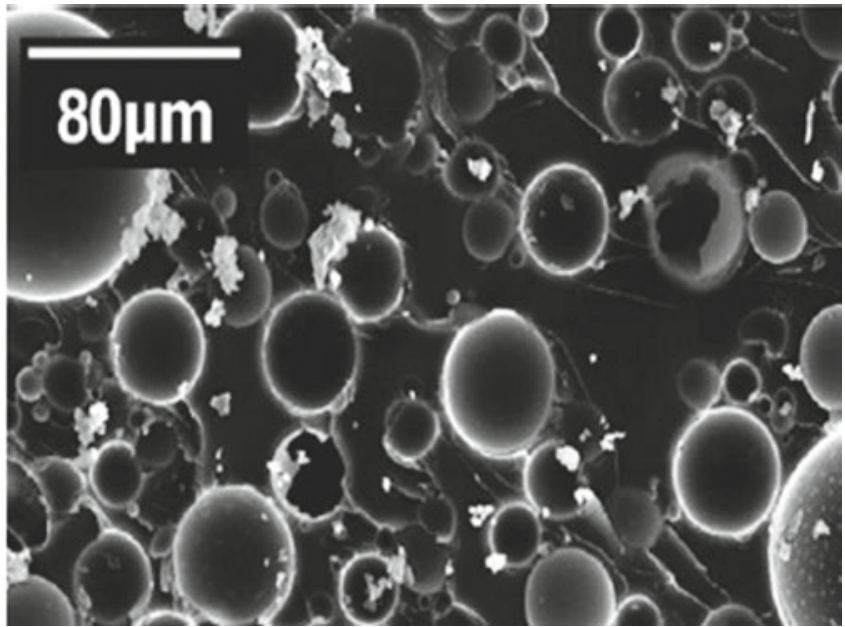

Figure 9. SEM micrograph of $30 \%$ filler content by weight.

\subsection{Testing for gradation in core}

Fly ash consists of a mixture of solid, hollow and composite particles possessing to a larger degree resemblance to spherical appearance. Hollow fly ash particles are termed as cenospheres while composite particles which consist of smaller solid and hollow spherical particles, are referred as plerospheres. Presence of gradation in prepared specimens is attributed towards these variable density particles present in fly ash which settle while solidifying at different depths. This phenomenon can be visualized as depicted in figure 2 .

Presence of gradation in prepared samples could be established as follows. A test slab of $10 \mathrm{~mm} \times 10 \mathrm{~mm} \times 10 \mathrm{~mm}$ is cut from the core sample (figure 3(a)). This is further cut into four thinner slices of dimensions $10 \mathrm{~mm} \times 10 \mathrm{~mm} \times$ $2.5 \mathrm{~mm}$ (figure $3(\mathrm{~b})$ ).

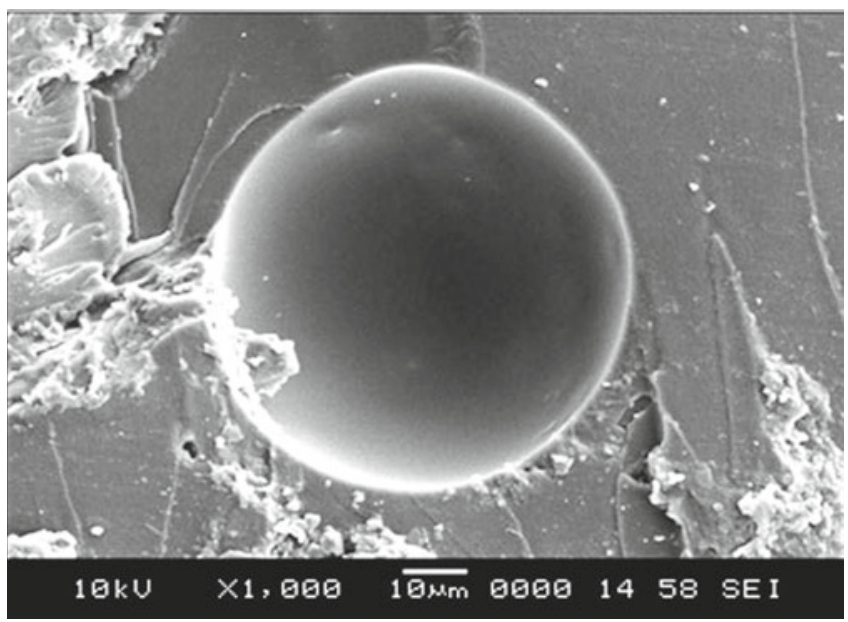

Figure 10. SEM of interface between filler and the matrix.

Another casting of rubber but without fly ash and having identical measurement is made. It is also sliced. The weights recorded in two cases are used to establish the content of filler. The weight $\%$ of fly ash in each slice could be estimated using the relation,

$\%$ weight of fly ash in slice

$=\{[$ FG core slice weight $(\mathrm{g})-$ slice weight of pure rubber $(\mathrm{g})] /$ weight of FG core slice $(\mathrm{g})\} \times 100$.

\subsection{Test set-up}

The test is carried out using Instron universal testing machine of model 4206 with loading capacity up to $150 \mathrm{KN}$ in accordance with ASTM standard (ASTM C 393-06 2006). Figure 4 shows the set-up of the test. 
Table 7. Jute-epoxy skin density.

\begin{tabular}{lrrr}
\hline Jute-epoxy (orientation in $\left.{ }^{\circ}\right)$ & $0^{\circ}-90^{\circ}$ & $30^{\circ}-60^{\circ}$ & $45^{\circ}-45^{\circ}$ \\
Density $\left(\mathrm{kg} / \mathrm{m}^{3}\right)$ & 1468 & $1451 \cdot 2$ & $1444 \cdot 3$ \\
\hline
\end{tabular}

Table 8. Sandwich density.

\begin{tabular}{lccc}
\hline $\begin{array}{l}\text { Fly ash } \\
\text { weight } \%\end{array}$ & C/H ratio & Orientation $\left(^{\circ}\right)$ & $\begin{array}{l}\text { Density } \\
\left(\mathrm{kg} / \mathrm{m}^{3}\right)\end{array}$ \\
\hline 20 & $0 \cdot 4$ & 0 & $1329 \cdot 48$ \\
20 & $0 \cdot 6$ & 30 & $1334 \cdot 47$ \\
20 & $0 \cdot 8$ & 45 & $1347 \cdot 34$ \\
30 & $0 \cdot 4$ & 30 & $1463 \cdot 21$ \\
30 & $0 \cdot 6$ & 45 & $1433 \cdot 86$ \\
30 & $0 \cdot 8$ & 0 & $1468 \cdot 22$ \\
40 & $0 \cdot 4$ & 0 & $1549 \cdot 73$ \\
40 & $0 \cdot 6$ & 30 & $1596 \cdot 96$ \\
40 & $0 \cdot 8$ & & $1562 \cdot 6$ \\
\hline
\end{tabular}

The crosshead displacement rate is maintained at $2 \mathrm{~mm} / \mathrm{min}$. The load deflection data is recorded at equal intervals up to a point at which the specimen shows the first sign of failure. From load deflection data compressive properties are evaluated. Specific compressive modulus and strength are estimated as per (2) and (3), respectively.

Specific modulus $=E / \rho \times g$,

Specific strength $=\sigma_{u} / \rho \times g$,

where $E=$ compressive modulus, $\sigma_{u}=$ ultimate strength and $\rho \times \mathrm{g}=$ weight density.

Deformation in core as a result of compressive forces is depicted in figure 5.

\subsection{Finite element analysis}

Sandwiches with FG core are modeled with 2D PLANE42 solid element and analysed simulating varying stiffness spring analogy (figure 6) by FEA using ANSYS 5.4.

Table 6 presents properties of FG core and jute/epoxy skin of sandwich construction used for FEA. Layer-wise Young's modulus and density of FG core are calculated for three weight fractions of fly ash from constituent properties to provide input to FEA for FG core.

Figure 7 shows finite element mesh of FG sandwich sample. Glue conditions are applied to eliminate relative movement of layers in core as well as between layers and faces of sandwich configuration.

\section{Results and discussion}

\subsection{Gradation and microstructure characterization}

Figure 8 presents results obtained from the gradation characterization by weight method. Values in the bracket represent
Table 9. Void content in FG cores.

\begin{tabular}{lccc}
\hline Wt $\%$ of fly ash & 20 & 30 & 40 \\
Void content $(\%)$ & 9.98 & $6 \cdot 13$ & 5.9 \\
\hline
\end{tabular}

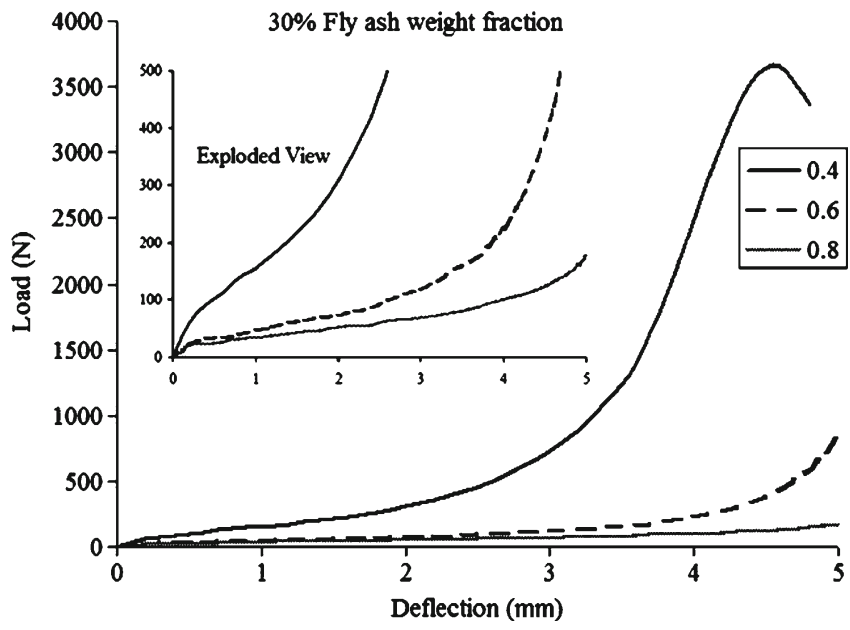

Figure 11. Load-deflection behaviour for varying $\mathrm{C} / \mathrm{H}$ ratio in compression of FG sandwich.

expected weight $\%$ of ash due to filler addition of 20, 30 and $40 \%$. As seen from figure 8 , layer-wise fly ash distribution clearly indicates the presence of piece-wise linear gradation in prepared samples.

Figures 9 and 10 present SEM images of FG core. Fly ash is seen to be well dispersed in the matrix as observed for $30 \%$ filler content from figure 9. Perfect bonding between filler and matrix is seen at higher magnification for $30 \%$ fly ash reinforcement (figure 10).

\subsection{Density and void content characterization}

Tables 7 and 8 present average density values obtained from the test for jute-epoxy skins and sandwiches.

Void content measures the voids in composite samples. Information on void content is useful as high void contents can significantly reduce the composites strength. Monitoring lot-to-lot void contents can also act as a measure of the consistency of the composite manufacturing process. Table 9 presents \% void content in FG cores.

For higher loading of fly ash, voids have less indicating advantage of higher filler content which could be due to the probability of these particles occupying the voids.

\subsection{Specific compressive properties}

Compression test is carried out on sandwich samples to evaluate specific compressive modulus and strength. The deflection plot of sandwich with varying $\mathrm{C} / \mathrm{H}$ ratio is presented in figure 11 . 
In the initial stages of the plot 11 , slope is less which subsequently increases due to contribution of ash-rich region at higher loads. This fact is observed for all $\mathrm{C} / \mathrm{H}$ ratios. With increase in $\mathrm{C} / \mathrm{H}$ ratio modulus and strength values seems to be decreasing by observing the nature of curves. This could be because of reduced volume of FG rubber core with increase in $\mathrm{C} / \mathrm{H}$ ratio making role of skins is more prominent than the core. Specific compressive modulus and strength are estimated using (2) and (3) are presented in table 10.

Results of table 10 are subjected to SN (signal to noise) ratio response using MINITAB commercially available package (MINITAB release 14 manual), for statistical analysis.

Table 10. Specific compressive modulus and strength.

\begin{tabular}{|c|c|c|c|c|c|c|}
\hline \multirow{2}{*}{$\begin{array}{l}\text { Sandwich coding } \\
W_{20} R_{0 \cdot 4} O_{0}\end{array}$} & \multicolumn{3}{|c|}{$\begin{array}{l}\text { Specific compressive modulus } \\
\left(\mathrm{MPa} / \mathrm{Nm}^{-1}\right)\end{array}$} & \multicolumn{3}{|c|}{$\begin{array}{l}\text { Specific compressive strength } \\
\left(\mathrm{MPa} / \mathrm{Nm}^{-1}\right)\end{array}$} \\
\hline & $52530 \cdot 2$ & $52609 \cdot 1$ & $51625 \cdot 5$ & $440 \cdot 5$ & $443 \cdot 5$ & $395 \cdot 15$ \\
\hline & 50674 & 52596 & & $347 \cdot 1$ & $360 \cdot 7$ & \\
\hline & $52602 \cdot 2$ & $50679 \cdot 1$ & & $447 \cdot 7$ & $418 \cdot 5$ & \\
\hline & $50666 \cdot 3$ & $50669 \cdot 1$ & & $412 \cdot 3$ & $349 \cdot 2$ & \\
\hline & $50673 \cdot 8$ & $52555 \cdot 3$ & & 359.4 & $372 \cdot 6$ & \\
\hline \multirow[t]{5}{*}{$W_{20} R_{0 \cdot 6} O_{30}$} & $43555 \cdot 8$ & $45901 \cdot 6$ & $44741 \cdot 6$ & $315 \cdot 8$ & $298 \cdot 5$ & $307 \cdot 5$ \\
\hline & $43557 \cdot 7$ & $45942 \cdot 1$ & & $299 \cdot 3$ & 321.4 & \\
\hline & $45921 \cdot 1$ & $43560 \cdot 5$ & & $301 \cdot 2$ & $310 \cdot 5$ & \\
\hline & $45941 \cdot 4$ & $43565 \cdot 2$ & & 308 & $302 \cdot 9$ & \\
\hline & $43571 \cdot 3$ & $45899 \cdot 5$ & & $308 \cdot 8$ & $308 \cdot 6$ & \\
\hline \multirow[t]{5}{*}{$W_{20} R_{0 \cdot 8} O_{45}$} & $39029 \cdot 1$ & $35829 \cdot 6$ & $37415 \cdot 7$ & 267.9 & 229.7 & $259 \cdot 45$ \\
\hline & $35815 \cdot 8$ & $38981 \cdot 2$ & & 253 & $222 \cdot 6$ & \\
\hline & 35807.9 & $39025 \cdot 9$ & & $271 \cdot 3$ & $271 \cdot 8$ & \\
\hline & $38999 \cdot 7$ & $35821 \cdot 3$ & & 274.9 & $269 \cdot 8$ & \\
\hline & $35831 \cdot 4$ & $39015 \cdot 3$ & & $265 \cdot 3$ & $268 \cdot 2$ & \\
\hline \multirow[t]{5}{*}{$W_{30} R_{0 \cdot 4} O_{30}$} & $60204 \cdot 5$ & $76348 \cdot 5$ & $68290 \cdot 1$ & $694 \cdot 2$ & $731 \cdot 7$ & $704 \cdot 15$ \\
\hline & $60242 \cdot 3$ & $76360 \cdot 2$ & & $699 \cdot 3$ & 694.9 & \\
\hline & 76364.9 & $60210 \cdot 9$ & & $725 \cdot 2$ & $696 \cdot 2$ & \\
\hline & $60209 \cdot 7$ & $76358 \cdot 9$ & & 689.9 & $720 \cdot 6$ & \\
\hline & $76358 \cdot 5$ & 60242.9 & & $703 \cdot 1$ & $686 \cdot 4$ & \\
\hline \multirow[t]{5}{*}{$W_{30} R_{0.6} O_{45}$} & $49922 \cdot 1$ & $41548 \cdot 2$ & $45730 \cdot 6$ & $394 \cdot 2$ & $385 \cdot 2$ & $395 \cdot 1$ \\
\hline & $41548 \cdot 2$ & $49909 \cdot 2$ & & $390 \cdot 6$ & $415 \cdot 8$ & \\
\hline & $41548 \cdot 2$ & $49926 \cdot 4$ & & $388 \cdot 9$ & $387 \cdot 5$ & \\
\hline & $41548 \cdot 2$ & $41548 \cdot 2$ & & $405 \cdot 7$ & $391 \cdot 3$ & \\
\hline & $49921 \cdot 2$ & $49886 \cdot 1$ & & $380 \cdot 4$ & 411.4 & \\
\hline \multirow[t]{5}{*}{$W_{30} R_{0 \cdot 8} O_{0}$} & $39075 \cdot 5$ & $31164 \cdot 2$ & $35105 \cdot 1$ & 300 & $273 \cdot 7$ & 262.7 \\
\hline & $31141 \cdot 5$ & $39046 \cdot 7$ & & $237 \cdot 8$ & $269 \cdot 3$ & \\
\hline & $39069 \cdot 2$ & $31164 \cdot 3$ & & $299 \cdot 4$ & $271 \cdot 1$ & \\
\hline & $31147 \cdot 1$ & $39060 \cdot 1$ & & 244.9 & $239 \cdot 7$ & \\
\hline & $39029 \cdot 6$ & $31152 \cdot 9$ & & $247 \cdot 3$ & $243 \cdot 8$ & \\
\hline \multirow[t]{5}{*}{$W_{40} R_{0 \cdot 4} O_{45}$} & $81114 \cdot 4$ & $83665 \cdot 2$ & 82374.8 & $765 \cdot 4$ & $759 \cdot 6$ & 739.6 \\
\hline & $83669 \cdot 1$ & $81112 \cdot 1$ & & $709 \cdot 4$ & $709 \cdot 1$ & \\
\hline & $81110 \cdot 6$ & $83635 \cdot 8$ & & $710 \cdot 5$ & $700 \cdot 3$ & \\
\hline & $83610 \cdot 3$ & 83599.5 & & 779.6 & $795 \cdot 2$ & \\
\hline & $81112 \cdot 5$ & $81118 \cdot 4$ & & $751 \cdot 2$ & $715 \cdot 7$ & \\
\hline \multirow[t]{5}{*}{$W_{40} R_{0 \cdot 6} O_{0}$} & 77109.9 & $67065 \cdot 1$ & 72104.9 & $571 \cdot 5$ & $531 \cdot 2$ & $546 \cdot 65$ \\
\hline & $67076 \cdot 2$ & $77115 \cdot 5$ & & $576 \cdot 6$ & $580 \cdot 7$ & \\
\hline & $77127 \cdot 1$ & $67074 \cdot 7$ & & $526 \cdot 2$ & $526 \cdot 9$ & \\
\hline & $67074 \cdot 2$ & $67080 \cdot 3$ & & $526 \cdot 6$ & $556 \cdot 8$ & \\
\hline & 77174.4 & 77151.4 & & $550 \cdot 9$ & $519 \cdot 1$ & \\
\hline \multirow[t]{5}{*}{$W_{40} R_{0 \cdot 8} O_{30}$} & $42634 \cdot 7$ & $61255 \cdot 6$ & $51938 \cdot 7$ & $479 \cdot 8$ & $484 \cdot 6$ & 481 \\
\hline & $61248 \cdot 9$ & $42651 \cdot 3$ & & $471 \cdot 1$ & $488 \cdot 5$ & \\
\hline & $42647 \cdot 3$ & $42647 \cdot 1$ & & $488 \cdot 2$ & $482 \cdot 6$ & \\
\hline & $61265 \cdot 7$ & $61200 \cdot 4$ & & $493 \cdot 5$ & $477 \cdot 8$ & \\
\hline & $42657 \cdot 1$ & $61178 \cdot 6$ & & $480 \cdot 4$ & $463 \cdot 5$ & \\
\hline
\end{tabular}


The outcome of statistical analysis is presented in table 11. In this $\mathrm{SN}$ response table, higher effect value represents a higher influence on specific modulus. From table 11, it can be seen that $\mathrm{C} / \mathrm{H}$ ratio has the most influence, while jute orientation the least. Figure 12 presents $\mathrm{SN}$ response graph for specific modulus. As depicted in figure 12, the best combination for specific modulus is samples with fly ash content of $40 \%, \mathrm{C} / \mathrm{H}$ of 0.4 and orientations of $30^{\circ} / 60^{\circ}$. Similar observations are made for specific compressive strength.

Higher resistance to compressive forces in subsequent layers makes compressive modulus to increase with filler content. Rubber being acting as a flexible core with increase in $\mathrm{C} / \mathrm{H}$ ratio bulging effect (figure 5) dominates causing decrease in compressive modulus. Effect of jute orientation is found to be negligible with $30^{\circ} / 60^{\circ}$ on higher side compared to other two. Rolling effect of fibers compared to stretching in $0^{\circ} / 90^{\circ}$ and nullifying effect in $45^{\circ} / 45^{\circ}$ might be the reason for its better performance.

Figures 13 and 14 present specific modulus and strength as a function of fly ash weight $\%$ for $0.4 \mathrm{C} / \mathrm{H}$ ratio as it has registered better performance compared to others. Effect of jute orientation has neglected as it is the least contributing factor towards both the specific compressive properties.

From both the figures (figures 13 and 14), it is clearly seen that with increase in filler content, specific properties show increasing trend. This increase in modulus can be attributed to FG cores compliance nature. With increase in filler content, relative movement of matrix in the network of fillers might be more uniform. Specific strength also seen to be

Table 11. Response of SN ratio - specific compressive modulus.

\begin{tabular}{lccc}
\hline & Fly ash weight\% & C/H ratio & Orientation \\
\hline Level 1 & 92.91 & 96.42 & 94.11 \\
Level 2 & 93.60 & 94.46 & 94.67 \\
Level 3 & 96.59 & 92.23 & 94.33 \\
Effect & 3.68 & 4.19 & 0.56 \\
Rank & 2 & 1 & 3 \\
\hline
\end{tabular}

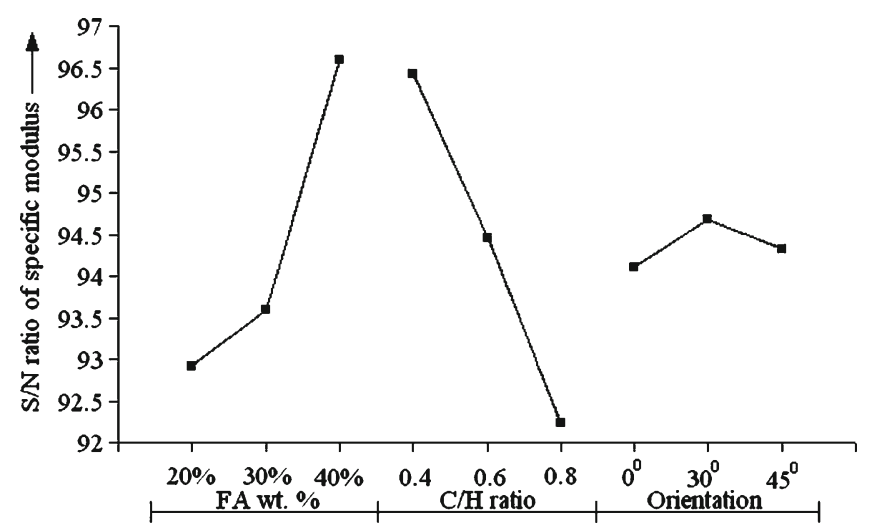

Figure 12. Response graph of $\mathrm{SN}$ ratio for specific modulus. increasing with fly ash content which increases sharply till $30 \%$, after which it stabilizes. This fact is very well augmented by good dispersion of filler in the matrix and better bonding between filler and the matrix as presented in SEM photographs (figures 9 and 10). Increasing strength could be due to consolidation stage of particle's relative movement in matrix. Drop in specific strength above $30 \%$ of reinforcement addition could be due to agglomeration effect creeping in for higher loading of fillers in the constrained matrix.

During compression test, many specimens failed to display a truly physical failure as they continued to yield till the end. Most of the FG samples failed due to delamination of the skin before squeezing out of the core. All the samples used in the test are failed at the skin and core interface, separating the skin.

\subsection{Finite element analysis}

Simulation of FG sandwiches is performed in FEA using Ansys 5.4 to determine specific compressive strength. Once the input properties are fed to Ansys software, FG sandwich is modeled and actual loads recorded in experimentation

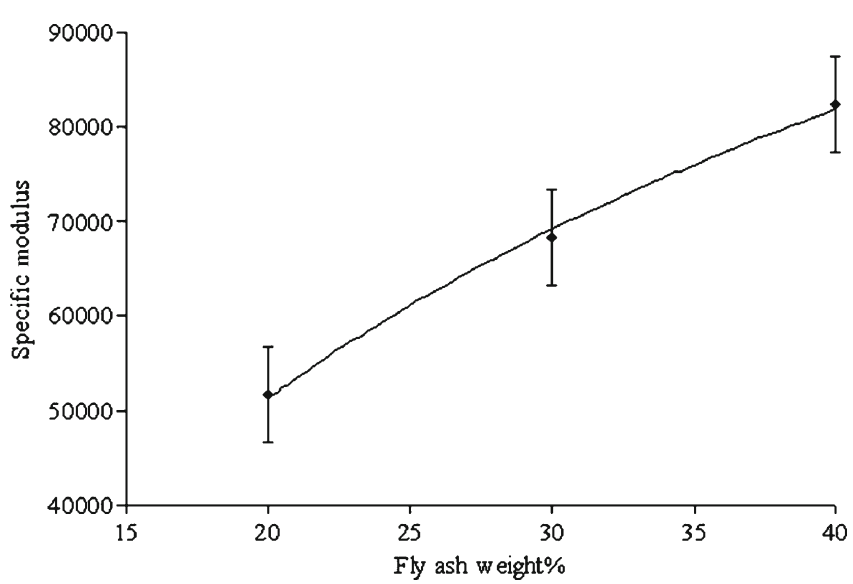

Figure 13. Specific modulus vs fly ash weight $\%$.

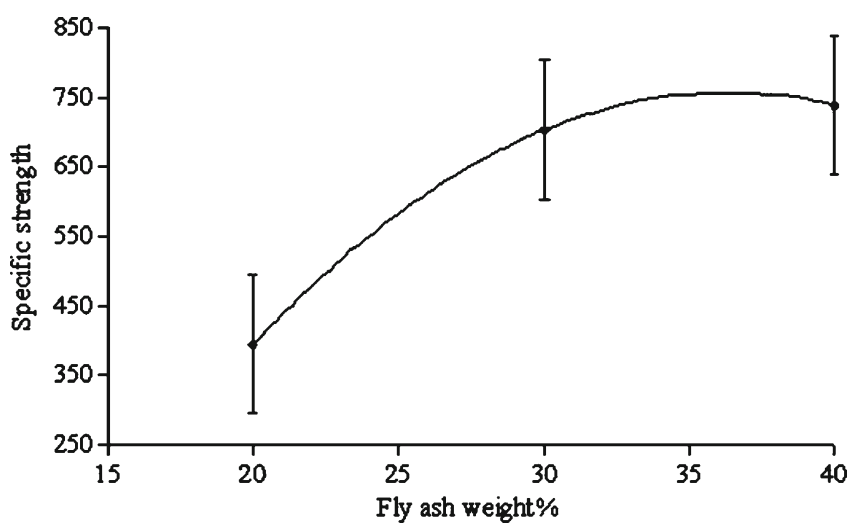

Figure 14. Specific strength vs fly ash weight $\%$. 

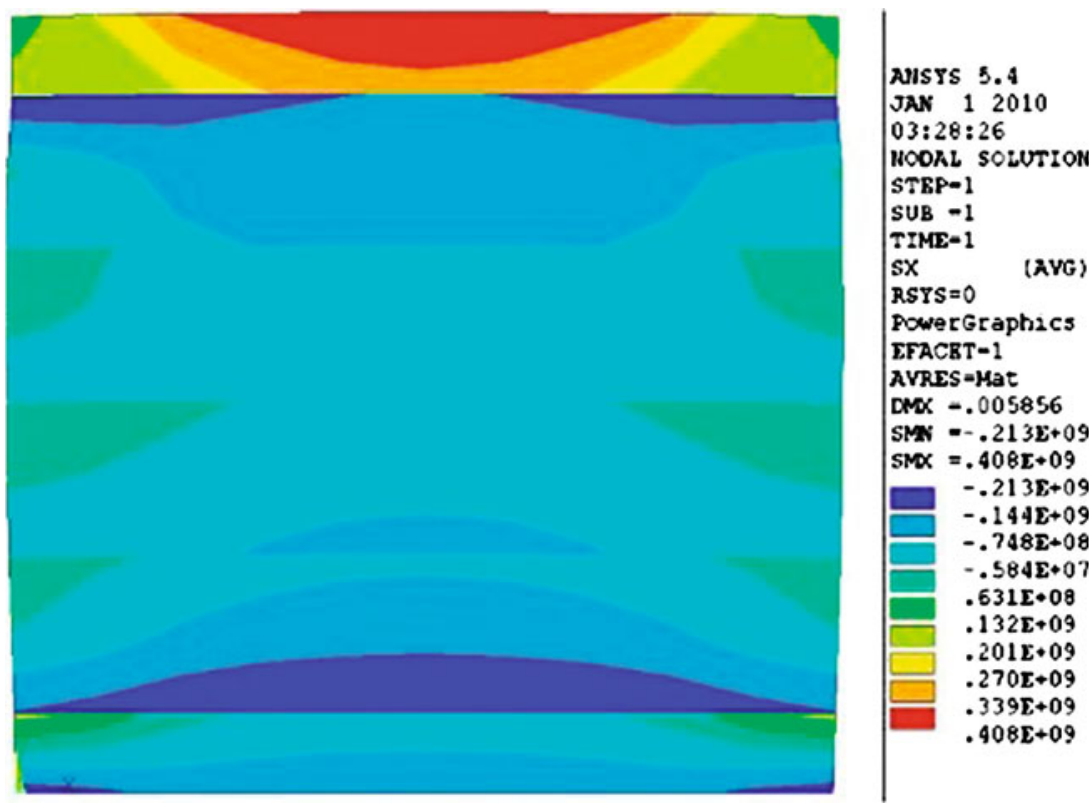

Figure 15. Stress plot of $W_{30} R_{0 \cdot 8} O_{0}$ sandwich in compression.
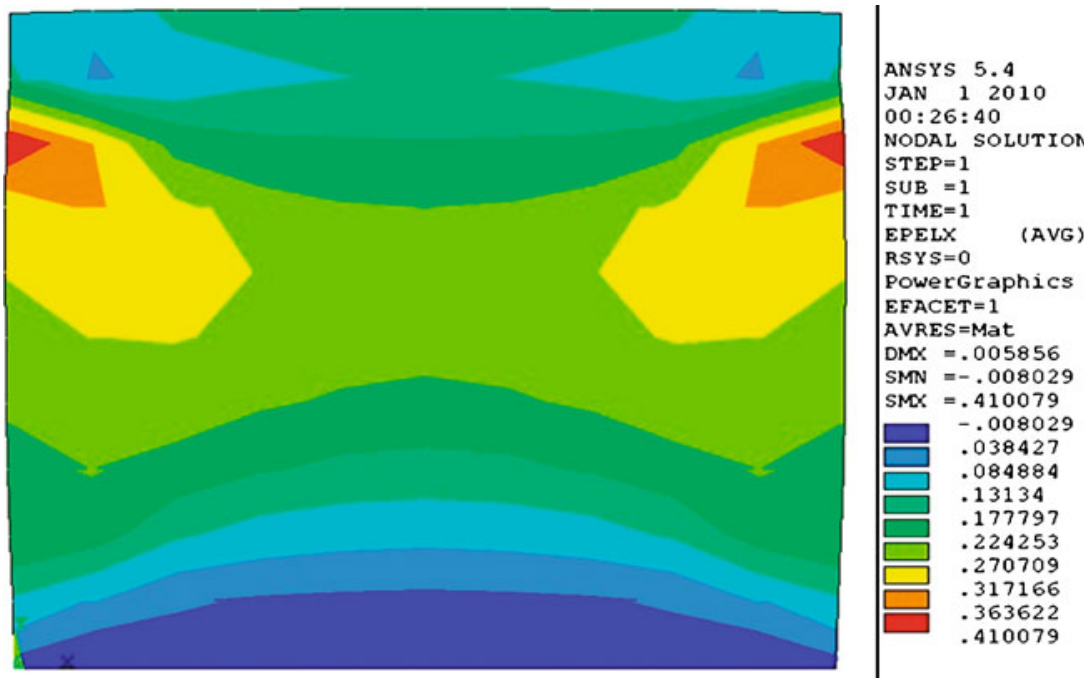

Figure 16. Plot of strain for $W_{30} R_{0.8} O_{0}$ sandwich in compression.

are applied. Figure 15 represents the plot for compressive stress in the sample for one typical loading case. The specific strength values obtained from FEA and through experimental route are compared in table 12.

Experimental and FEA values match very well. It could be observed that FEA slightly overestimates the compressive strength. This could be due to the inhomogenity creeping in during the processing of samples. Strain plot is presented in figure 16.

From strain plot it could be noted that higher strain values are evident in upper layers than subsequent lower ones. This is also reflected in load deflection behaviour (figure 11). This is an indication of rubber-rich top layers and ash-rich bottom layers which implies the presence of gradation in samples.
Table 12. Specific compressive strength results $\left(\mathrm{MPa} / \mathrm{Nm}^{-1}\right)$ in sandwich.

\begin{tabular}{lccc}
\hline Sandwich configuration & FEA & Experimental & \%Error \\
\hline$W_{20} R_{0.4} O_{0}$ & $395 \cdot 15$ & 389.27 & 1.51 \\
$W_{20} R_{0.6} O_{30}$ & 320.48 & 307.5 & 4.22 \\
$W_{20} R_{0.8} O_{45}$ & 283.40 & 259.45 & 9.23 \\
$W_{30} R_{0.4} O_{30}$ & 739.67 & 704.15 & 5.04 \\
$W_{30} R_{0.6} O_{45}$ & 405.48 & $395 \cdot 1$ & 2.63 \\
$W_{30} R_{0.8} O_{0}$ & 267.83 & 262.7 & 1.95 \\
$W_{40} R_{0.4} O_{45}$ & 743.32 & 739.6 & 0.50 \\
$W_{40} R_{0.6} O_{0}$ & 557.61 & 546.65 & 2.00 \\
$W_{40} R_{0.8} O_{30}$ & 497.47 & 481 & 3.42 \\
\hline
\end{tabular}




\section{Conclusions}

Processing and testing of sandwiches with FG core in flatwise compression mode is presented in this paper. The gradation in the core is assessed by weight method. Results affirm the realization of functional gradation in core because of preferential setting of the varying density ash particles at different depths.

An experimental investigation of specific compressive modulus and strength of sandwich is carried out. It shows that $\mathrm{C} / \mathrm{H}$ ratio is observed to be prominent factor in modulus and strength. With increase in filler content, modulus as well as strength are increased. Highest modulus and strength are recorded for $40 \%$ by weight of filler, $\mathrm{C} / \mathrm{H}$ ratio of 0.4 and $30^{\circ} / 60^{\circ}$ skin orientation. For $0.4 \mathrm{C} / \mathrm{H}$ ratio, specific strength is observed to increase sharply up to $30 \%$ filler content beyond which no significant increase is recorded. SEM micrographs support this fact by showing perfect bonding and good dispersion of fillers in the matrix at relatively higher amounts of filler (30\%). Agglomeration effect beyond $30 \%$ filler content might have resulted in dropping the strength. Specific modulus and strength values obtained are sufficient for low tech and low cost applications in composite structures.

Modeling of the FG sandwich in FEM with piece-wise linear gradation are quite close (up to 9\%) to experimental values suggesting that the gradation of filler within layer is linear and overall gradation to be piece-wise linear.

\section{References}

Anderson T A 2003 Compos. Struct. 60265

Apetre N A, Sankar B V, Ambur D R 2003 in Proceedings of the 44th AIAA/ASME/ASCE/AHS/ASC structures, structural dynamics and materials conference, Functionally graded sandwich core with arbitrary variation in properties (Washington DC: AIAA, CDROM)

ASTM C 274-07 1999 West Conshohocken (PA: ASTM International)

ASTM C 393-06 2006 Standard test method for core shear properties of sandwich constructions by beam flexure (PA: ASTM International)

Atckinson R 1997 Reinf. Plast. 4130

Blackley D C 1997 Polymer lattices: science and technology application of lattice (London: Chapman and Hall)

Bull P H and Edgren F 2004 Compos. Engin. Part B 35535
Chakraborty A, Gopalakrishnan S and Reddy J N 2003 Int. J. Mech. Sci. 45519

Dai J and Thomas Hahn H 2003 Compos. Struct. 61247

Daniel I M and Abot J L 2000 Compos. Sci. Technol. 602455

Davalos J F, Qiao P Z, Xu X F, Robinson J and Barth K E 2001 Compos. Struct. $\mathbf{5 2} 441$

Doddamani M R and Kulkarni S M 2009 in Proceedings of interdisciplinary conference on chemical, mechanical and materials engineering (2009 ICCMME), (Australia: Australian Institute of High Energetic Materials) 314

Doddamani M R, Kulkarni S M and Kishore 2011 Polym. Compos. 321541

Doddamani M R and Kulkarni S M 2012 Mech. Compos. Mater. 48 89

Evans A G, Hutchinson J W, Fleck N A, Ashby M F and Wadley H N G 2001 Progr. Mater. Sci. 46309

Gdoutos E E and Daniel I M 2008 J. Theor. Appl. Mech. 35105

Keller T 2006 Material tailored use of FRP composites in bridge and building construction (Switzerland: Swiss Federal Institute of Technology Lausanne)

Kirugulige M S, Kitey R and Tippur H V 2005 Compos. Sci. Technol. 651052

Kishore, Kulkarni S M, Sharathchandra S and Sunil D 2002 Polym. Test. 21763

Ma L S and Wang T J 2004 Internat. J. Sol. Struct. 4185

Manalo A C, Aravinthan T, Karunasena W and Islam M M 2010 Compos. Struct. 92984

Montgomery D C 2001 Design and analysis of experiments (New York: Wiley) 5th ed

Mouritz A P and Thomson R S 1999 Compos. Struct. 44263

Najafizadeh M M and Eslami M R 2002 Internat. J. Mech. Sci. 44 2479

Rocca S V and Nanni A 2005 Composites in construction. in Third international conference (USA: University of Miami)

Ross P J 1988 Taguchi techniques for quality engineering (New York: McGraw-Hill Book company)

Russo A and Zuccarello B 2007 Compos. Struct. 81575

Sankar B V 2001 Compos. Sci. Technol. 61689

Shen H S 2002 Internat. J. Solids Struct. 395991

Shen H S and Leung A Y T 2003 J. Eng. Mech. 129414

Shen H S 2005 Compos. Sci. Technol. 651675

Venkata Dinesh Muthyala 2007 Composite sandwich structure with grid stiffened core, Master thesis (Graduate Faculty of the State University and Agricultural and Mechanical College, Louisiana)

Vinson J 1999 The behaviour of sandwich structures of isotropic and composite materials (Pennsylvania: Technomic)

Wadley H N G, Fleck N A and Evans A G 2003 Compos. Sci. Technol. 632331 